\section{Conclusion}

The mortality rate in patients with polycythaemia secondary to hypoxic lung disease rises with decreasing $\mathrm{FEV}_{1}$ (Renzetti et al., 1966; Burrows and Earle, 1969), and patients with an FEV below 0.751 . have a five-year survival rate of only $25 \%$. Hypercapnia and cardiac abnormalities affect prognosis adversely independently of their relation to air flow obstruction, and Baldwin et al. (1949) found that the four-year mortality of patients with cor pulmonale was $73 \%$. All our patients are therefore in the poor-prognosis group. We consider that exchange transfusion is a rapid and safe method of reducing red cell mass, P.C.V., and blood viscosity and that this produces a worth-while amelioration of symptoms lasting about six months, after which exchange transfusion can be repeated.

We should like to thank Drs. N. C. Oswald and F. H. Scadding for helpful discussion and constructive criticism and for allowing one of us (B.D.W.H.) to study patients under their care. It is a pleasure to acknowledge the help of the hospital physics department, Guy's Hospital; of Dr. V. R. McCready and Miss J. Lawford, of the diagnostic isotopes department, Royal Marsden Hospital, who performed the blood volume measurements; of $\mathrm{Mr}$. $\mathrm{K}$. Twinn, of the physics department, Guy's Hospital Medical School, who performed the blood viscosity estimations; and of Miss J. Hibbert for her invaluable secretarial help.

\section{References}

Agarwal, J. B., Paltoo, R., and Palmer, W. H. (1970). fournal of Applied Physiology, 29, 866 .

Auchincloss, J. H., and Duggan, J. J. (1957). American fournal of Medicine, $22,74$.

Baldwin, E. de F., Cournand, A., and Richards, D. W. (1949). Medicine, $28,201$.

Burrows, B., and Earle, R. H. (1969). New England fournal of Medicine, 280, 397 .

Chamberlain, D. A., and Millard, F. J. C. (1963). Quarterly fournal of Medicine, 32, 341.

Dintenfass, L., and Read, J. (1968). Lancet, 1, 570

Dintenfass, L., and Read, J. (1968). Lancet, 1, 570.

Gregory, R. J. (1971b). Acta Medica Scandinavica, 189, 551.

Hume, R. (1968). British fournal of Haematology, 15, 131

Laws, J. W., and Heard, B. E. (1962). British fournal of Radiology, 35, 750. Medical Research Council. (1965). Lancet, 1, 775.

Mitchell, R. S., Webb, W. C., and Filley, G. F. (1964). American Review of Respiratory Diseases, 89, 878.

Pengelly, C. D. R. (1966). Lancet, 2, 1381.

Pengelly, C. D. R. (1969). Postgraduate Medical Fournal, 45, 583.

Renzetti, A. D., McClement, J. H., and Litt, B. D. (1966). American fournal of Medicine, 41, 115.

Segal, N., and Bishop, J. M. (1966). Fournal of Clinical Investigation, 45, 1555. Segal, N., and Bishop, J. M. (1967). Clinical Science, 32, 527.

Semmens, J. M. (1971). M.D. Thesis, London.

Shaw, D. B., and Simpson, T. (1961). Quarterly fournal of Medicine, 30, 135.

Sunder-Plassman, L., Klövekorn, W. P., Holper, K., Hase, U., and Messmer, K. (1970). Sixth Conference of the European Society for Microcirculation, Aalberg.

\title{
Influence of Blood Viscosity on Blood Flow and the Effect of Low Molecular Weight Dextran
}

\author{
JOHN A. DORMANDY
}

British Medical fournal, 1971, 4, 716-719

\section{Summary}

Changes in whole blood viscosity are related to changes in the leg blood flow during infusions of low-molecularweight dextran and Hartmann's solution. A close inverse correlation exists between changes in viscosity and blood flow, the change in blood flow being about three times greater than the change in blood viscosity. The dextran and Hartmann's solution had a similar effect on blood viscosity and blood flow if corrections are made for the difference in haemodilution.

\section{Introduction}

There are three basic determinants of peripheral blood flow: the perfusion pressure, the morphology of the vessels, and the viscosity of the blood. In the past attention has been focused almost exclusively on the first two. In more recent years an abnormally high blood viscosity has been found in a number of vascular and haematological diseases (Wells, 1966; Skovborg et al., 1968; Dintenfass, 1969; Dormandy, 1970). An abnormality of blood viscosity, rather than pathological changes in the vessels or the heart, may well be the more important aetiological factor in many diseases characterized by poor circulation. However, the exact relationship, in humans,

\footnotetext{
Royal Free and Royal Northern Hospitals, London

JOHN A. DORMANDY, F.R.C.s., Senior Surgical Registrar, also Honorary Lecturer, Institute of Basic Medical Sciences, Royal College of Surgeons
of England
}

between changes in the blood viscosity and blood flow has rarely been studied; it was one of the aims of the present investigation to measure this relationship.

Changes in blood viscosity and blood flow were observed during intravenous infusions. One of the solutions used for the infusions was low-molecular-weight (L.M.W.) dextran, which enjoys a considerable vogue as a blood flow improver and has been thought to have a specific effect on blood viscosity. To assess whether this dextran alters blood viscosity simply by haemodilution or by a more specific effect the results were compared with another group of subjects who received an equal volume of Hartmann's solution.

\section{Method}

The whole blood viscosity, packed cell volume (P.C.V.), leg blood flow, as well as the arterial and venous blood pressures were measured in 19 patients receiving intravenous infusions before elective abdominal surgery. Patients with evidence of haematological or cardiovascular disease, on history or examination, were excluded from the study. Ten patients received $10 \%$ dextran in saline and 10 Hartmann's solution. One patient was given both solutions at different times. Measurements were made after premedication and before induction of anaesthesia. Initial readings, begun 60 minutes after premedication with papaveretum and scopolamine or pethidine and atropine, were repeated until a steady state had been reached, when a sample of venous blood was withdrawn and an intravenous infusion set up in the arm. Then $500 \mathrm{ml}$ of the solution to be infused was given over a period of 10 to 20 minutes. At the end of the infusion another $10-\mathrm{ml}$ venous blood sample was withdrawn and all the measurements were repeated. Further readings were taken 10 minutes later. 
Whole Blood Viscosity at Shear Rate of $230 \mathrm{sec}^{-1}$, P.C.V., and Calf Blood Flow before (A), at the End (B), and 10 Minutes after the End (C) of Infusions with $500 \mathrm{ml}$ of Low-molecular weight Dextran or Hartmann's Solution

\begin{tabular}{|c|c|c|c|c|c|c|c|c|c|c|c|c|}
\hline \multicolumn{5}{|c|}{ Whole Blood Viscosity (centipoise) } & \multicolumn{3}{|c|}{ P.C.V. (\%) } & \multicolumn{5}{|c|}{ Calf Blood Flow (ml/100 ml/min) } \\
\hline $\mathbf{A}$ & B & C & $A$ to $B$ & B to $\mathrm{C}$ & $\mathbf{A}$ & B & C & $\mathbf{A}$ & $\mathbf{B}$ & $\mathbf{C}$ & A to $B$ & B to $C$ \\
\hline \multicolumn{13}{|c|}{ Infusion of Hartmann's Solution } \\
\hline $\begin{array}{l}4 \cdot 55 \\
4 \cdot 5 \\
5 \cdot 3 \\
4 \cdot 2 \\
5 \cdot 15 \\
3.95 \\
5 \cdot 1 \\
4 \cdot 7 \\
5 \cdot 35 \\
4 \cdot 9\end{array}$ & $\begin{array}{l}\mathbf{4} \cdot 25 \\
4 \cdot 0 \\
4 \cdot 7 \\
3 \cdot 7 \\
4 \cdot 6 \\
3 \cdot 5 \\
\mathbf{4} \cdot \mathbf{4} \\
\mathbf{4} \cdot 2 \\
4 \cdot 8 \\
\mathbf{4} \cdot \mathbf{4}\end{array}$ & $\begin{array}{l}\overline{4} \overline{2} \\
4 \cdot 5 \\
\overline{-} \\
3 \cdot \overline{7} \\
4 \cdot 65 \\
4 \cdot 3 \\
5 \cdot 0 \\
4 \cdot 5\end{array}$ & $\begin{array}{l}-7 \% \\
-11 \% \\
-11 \% \\
-12 \% \\
-11 \% \\
-11 \% \\
-14 \% \\
-11 \% \\
-10 \% \\
-10 \%\end{array}$ & $\begin{array}{l}-\overline{5 \%} \\
+4 \% \\
-\overline{-} \\
+6 \% \\
+6 \% \\
+2 \% \\
+4 \% \\
+2 \%\end{array}$ & $\begin{array}{l}39 \\
40 \\
53 \\
45 \\
50 \\
37 \cdot 5 \\
47 \\
45 \cdot 5 \\
52 \cdot 5 \\
47\end{array}$ & $\begin{array}{l}37 \\
34 \\
49 \\
38 \\
48 \\
34 \\
43 \\
43 \\
49 \\
43\end{array}$ & $\begin{array}{l}3 \overline{36 \cdot 5} \\
47 \\
= \\
36 \\
44 \\
44 \\
50 \\
44\end{array}$ & $\begin{array}{l}1 \cdot 9 \\
1 \cdot 8 \\
2 \cdot 1 \\
1 \cdot 15 \\
4 \cdot 3 \\
2 \cdot 0 \\
6 \cdot 2 \\
2 \cdot 4 \\
2 \cdot 1 \\
6 \cdot 4\end{array}$ & $\begin{array}{l}2 \cdot 2 \\
2 \cdot 0 \\
2 \cdot 3 \\
1 \cdot 5 \\
5 \cdot 0 \\
2 \cdot 2 \\
7.5 \\
3 \cdot 4 \\
2 \cdot 8 \\
7 \cdot 7\end{array}$ & $\begin{array}{l}1 . \overline{8} \\
2 \cdot 3 \\
\bar{Z} \\
1 \cdot \overline{8} \\
6 \cdot 7 \\
3 \cdot 3 \\
2 \cdot 4 \\
6 \cdot 2\end{array}$ & $\begin{array}{l}+16 \% \\
+11 \% \\
+10 \% \\
+30 \% \\
+16 \% \\
+10 \% \\
+21 \% \\
+42 \% \\
+33 \% \\
+21 \%\end{array}$ & $\begin{array}{l}-\overline{10} \% \\
0 \\
=-\overline{18} \% \\
-10 \% \\
=3 \% \\
=14 \% \\
-19 \%\end{array}$ \\
\hline \multicolumn{13}{|c|}{ Infusion of Low-molecular-weight Dextran } \\
\hline $\begin{array}{l}5 \cdot 0 \\
6 \cdot 05 \\
5 \cdot 25 \\
5 \cdot 1 \\
4 \cdot 35 \\
5 \cdot 25 \\
4 \cdot 8 \\
4 \cdot 2 \\
7 \cdot 55 \\
4 \cdot 4\end{array}$ & $\begin{array}{l}4 \cdot 15 \\
4 \cdot 65 \\
4 \cdot 4 \\
4 \cdot 5 \\
4 \cdot 05 \\
4 \cdot 3 \\
4 \cdot 25 \\
3.95 \\
6 \cdot 05 \\
3.95\end{array}$ & $\begin{array}{l}4 \cdot 0 \\
4 \cdot 45 \\
4 \cdot 2 \\
4 \cdot 15 \\
-\overline{4} \cdot 1 \\
4 \cdot 0 \\
5 \cdot 75 \\
4 \cdot 0\end{array}$ & $\begin{array}{l}-17 \% \\
-23 \% \\
-16 \% \\
-12 \% \\
-7 \% \\
-18 \% \\
-11 \% \\
-6 \% \\
-20 \% \\
-10 \%\end{array}$ & $\begin{array}{l}-4 \% \\
-4 \% \\
-5 \% \\
-8 \% \\
-\overline{50} \\
-6 \% \\
-\overline{5 \%} \\
+1 \%\end{array}$ & $\begin{array}{l}45 \\
50 \\
47 \\
49 \cdot 5 \\
45 \\
42 \\
46 \\
44 \\
60 \\
42 \cdot 5\end{array}$ & $\begin{array}{l}38 \\
42 \\
40 \\
42 \cdot 5 \\
40 \\
38 \\
41 \\
40 \\
53 \\
38 \cdot 5\end{array}$ & $\begin{array}{l}37 \\
41 \\
38 \\
41 \\
35 \\
38 \cdot 5 \\
51 \\
38 \cdot 5\end{array}$ & $\begin{array}{l}2 \cdot 6 \\
2.5 \\
3 \cdot 4 \\
3 \cdot 5 \\
4 \cdot 0 \\
1.7 \\
2 \cdot 7 \\
1.3 \\
4 \cdot 4\end{array}$ & $\begin{array}{l}3.5 \\
3.8 \\
4.4 \\
4 \cdot 1 \\
4.5 \\
1.9 \\
1.9 \\
3.2 \\
1.5 \\
6.0\end{array}$ & $\begin{array}{l}3.9 \\
4.4 \\
4.0 \\
\frac{1}{1.8} \\
1.8 \\
1.6 \\
6.1\end{array}$ & $\begin{array}{l}+35 \% \\
+52 \% \\
+29 \% \\
+17 \% \\
+12 \% \\
+12 \% \\
+19 \% \\
+15 \% \\
+36 \%\end{array}$ & $\begin{array}{l}+11 \% \\
+16 \% \\
-\underline{2} \% \\
-5 \% \\
+7 \% \\
+2 \%\end{array}$ \\
\hline
\end{tabular}

The blood samples were anticoagulated with 125 IU of solid lithium heparin and viscosity measurements carried out within 15 minutes with a Wells-Brookfield microviscometer. The shear stress was recorded after exposing $0 \cdot 8-\mathrm{ml}$ blood samples to a constant shear rate of $230 \mathrm{sec}^{-1}$ for four minutes at a temperature of $37^{\circ} \mathrm{C}$; the viscosity was calculated from the ratio of shear stress to shear rate. The P.C.V. of all the samples was measured.

Temperature-compensated mercury-in-rubber strain gauge plethysmography was used to determine the calf blood flow.

\section{Results}

BLOOD VISCOSITY AND BLOOD FLOW IN LEG

The initial blood viscosity, P.C.V., and the average rate of infusion were not significantly different in the two groups. The P.C.V. and viscosity at a shear rate of $230 \mathrm{sec}^{-1}$ before the infusion, at the end of the infusion, and 10 minutes later are shown in the Table. The percentage changes in the viscosity between the first two and the second two readings are also shown. The blood viscosity fell during transfusion in all patients. The decrease in patients receiving L.M.W. dextran was $14 \%$ (S.D. 5.6) at the end of the transfusion and a further 4.5\% (S.D. 2.5) 10 minutes later. In patients receiving Hartmann's solution an initial fall of $10.8 \%$ (S.D. 1.7) during the transfusion was followed by a $3 \%$ rise (S.D. 3.4) in the next 10 minutes. The difference between the two groups is significant 10 minutes after the transfusion $(P=0.001)$ but not immediately after the transfusion $(P=0 \cdot 1)$.

The blood flow before, at the end, and 10 minutes after the end of the transfusion as well as the percentage changes in the blood flow during the transfusion and the following 10 minutes are also shown in the Table. There is considerable variation in the individual resting blood flow but no significant difference between the two groups. (Mean blood flow in the group receiving Hartmann's solution was $3.0 \mathrm{ml} / 100 \mathrm{ml} / \mathrm{min}$ (S.D. 1.85) while the corresponding figure for the group receiving dextran was 2.9 with an S.D. of 0.95 .) At the end of the transfusion of dextran there was a mean increase in calf blood flow of $25 \cdot 2 \%$ (S.D. 13.8), while after the transfusion of Hartmann's solution the increase was $21 \%$ (S.D. 10.8), the difference between the two groups being insignificant. However, the changes in flow over the next 10 minutes were significantly different $(P=0.002)$; the flow increased by a further $4.8 \%$ in the group receiving dextran compared with a decrease of $10.5 \%$ in the group infused with Hartmann's solution.

Changes in blood flow tended to reflect changes in blood

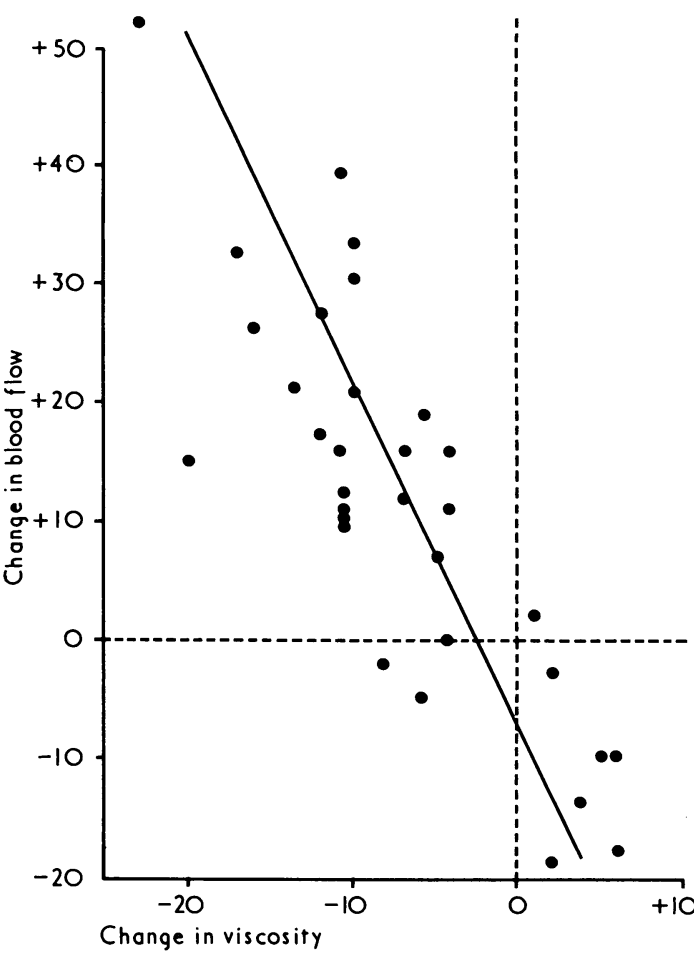

FIG. 1-Relationship between percentage changes in whole blood viscosity and calf blood flow during and after infusions of $500 \mathrm{ml}$ of L.M.W. dextran and Hartmann's solution.

viscosity; a fall in blood viscosity was accompanied by an increase in the blood flow. Fig. 1 shows the percentage change in viscosity plotted against the percentage change in the accompanying flow in each patient. The correlation between changes in blood viscosity and blood flow was close, the correlation coefficient being $-0 \cdot 8$ (S.E. $0 \cdot 25)$ for the patients receiving Hartmann's solution and -0.7 (S.E. 0.25$)$ for those receiving dextran. The formula for the regression line shown in Fig. 1 is: percentage change in flow $=3.05$ (percentage change in viscosity) $-5 \cdot 5$.

There was no significant difference in the effect of viscosity on blood flow in the two groups of patients. Therefore the effect of alteration in blood viscosity on blood flow was unrelated to the type of fluid used for infusion. The greater increase in flow observed with L.M.W. dextran was no more than would be expected from the greater fall in viscosity.

The perfusion pressure did not change markedly in any of the patients; on average it decreased by $4 \mathrm{~mm} \mathrm{Hg}$ at the end of the study. 


\section{EFFECT OF DEXTRAN ON BLOOD VISCOSITY}

The greater fall in viscosity when L.M.W. dextran was infused compared with an equal volume of Hartmann's solution was accompanied by a similar difference in haemodilution. At similar rates of transfusion the dextran caused greater haemodilution than Hartmann's solution. The P.C.V. was lowered at the end of the transfusion by a mean of $5.8 \%$ (S.D. 1.5) in patients given dextran compared with $3.8 \%$ (S.D. 1.6) in patients receiving Hartmann's solution (see Table). After infusion the dextran continued to cause movement of fluid into the vascular space so that 10 minutes later the P.C.V. had decreased by a further $1 \cdot 6 \%$ (S.D. 0.9 ). In contrast, 10 minutes after the end of the transfusions with Hartmann's solution the P.C.V. had begun to increase ( $+0.9 \%$, S.D. 1.4), indicating the movement of fluid out of the circulation. The difference in the P.C.V. shift of the two groups is significant both at the end of the transfusion $(P=0.02)$ and 10 minutes after the transfusion $(P=0.001)$.

The changes in viscosity have to be examined against this background of varying haemodilution. To determine whether these differences in the viscosity changes are merely due to the increased haemodilution which occurs with L.M.W. dextran the fall in blood viscosity has to be related to the fall in P.C.V. for each group of patients. The normal relationship between viscosity and P.C.V. has been determined; within the physiological range the logarithm of the viscosity is linearly related to the P.C.V. (Dormandy, 1970). This finding agrees with those of Gregerson et al. (1963) and of Chien et al. (1966). Therefore the logarithm of the viscosity of each patient at the beginning, the end, and 10 minutes after the transfusion was plotted against the corresponding P.C.V.

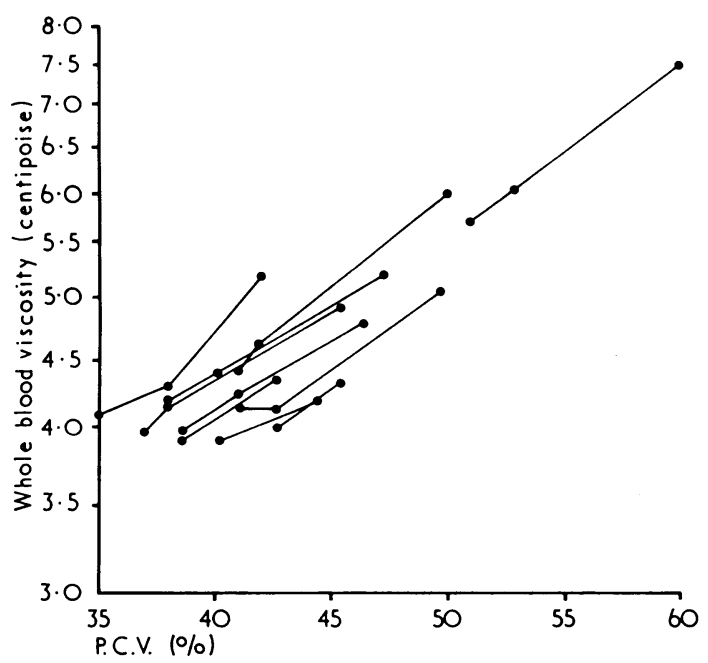

FIG. 2-Logarithm of the whole blood viscosity at a shear rate of $230 \mathrm{sec}^{-1}$ plotted against the P.C.V. The lines connect the readings for individua patients at the beginning, the end, and 10 minutes after the end of an infusion of $500 \mathrm{ml}$ of L.M.V. dextran.

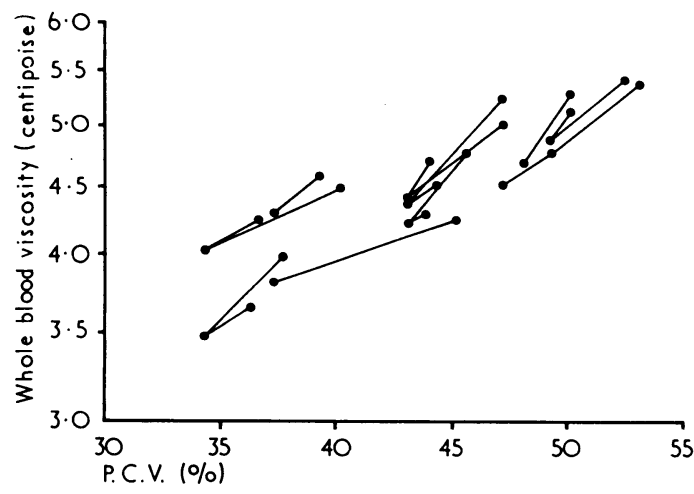

FIG. 3-Similar representation to that used in Fig. 2, for patients receiving $500 \mathrm{ml}$ of Hartmann's solution.
Fig. 2 shows the results in the group receiving the dextran and Fig. 3 the results in those receiving Hartmann's solution. In both sets of results it can be seen that changes in viscosity follow closely the changes in the P.C.V. The average slope of the lines in Fig. 2 is given by the formula $\log \eta=0.012$ P.C.V. (S.D. $=0.004)$ and in Fig. 3 by the formula $\log \eta=0.014$ P.C.V. (S.D. = 0.005). Since the difference in the slopes of these lines is not significant, the change in viscosity due to the infusion of either the dextran or Hartmann's solution is only what would be expected from the haemodilution effect. Therefore the greater decrease in viscosity observed with the infusion of L.M.W. dextran is merely due to the greater haemodilution.

\section{Discussion}

There have been reports in recent years of an abnormally high blood viscosity in various circulatory disorders such as shock (Yao and Shoemaker, 1966), diabetes (Skovborg et al., 1966), coronary disease (Gregerson et al., 1963; Mayer, 1964 Dintenfass et al., 1966), and peripheral arterial disease (Dormandy, 1970). Underlying such a connexion is the assumption of an inverse relationship between blood viscosity and blood flow. Though this was originally suggested by Poiseuille (1846), based on his studies of Newtonian fluids in rigid tubes, this relationship has never been investigated directly in humans. Gelin et al. (1961), Carey et al. (1965), and Gianelli et al. (1965) measured the effect of various intravenous infusions on blood flow but did not correlate the changes in blood flow with the changes in viscosity or P.C.V.

The present investigation showed a good correlation between changes in the blood viscosity and flow which was unrelated to the solution used to induce the changes in the viscosity. A particular change in blood viscosity resulted in an opposite and about three times greater change in blood flow.

This critical effect of blood viscosity on blood flow suggests that severe circulatory deficiency may be caused by quite small increases in blood viscosity as well as narrowing of the vessels.

Since the introduction of low-molecular-weight dextran into clinical use many reports have suggested its usefulness as a blood flow improver. Lowering of the plasma viscosity (Groth and Thoren, 1965) and lowering of the whole blood viscosity (Carey et al., 1965; Groth, 1966; Yao and Shoemaker, 1966; Langsjoen and Inmon, 1968) have been suggested as possible mechanisms leading to improved flow. However, only Yao and Shoemaker corrected for haemodilution, by converting all the samples to a constant P.C.V. The present results confirmed that, volume for volume, infused dextran lowers the blood viscosity more than Hartmann's solution. This is, however, no more than would be expected from the greater haemodilution with dextran due to its hypertonicity. Therefore L.M.W. dextran has no specific effect on blood viscosity or blood flow.

This work was made possible by the encouragement and help of Dr. J. Bullogh, anaesthetist to the Dartford Group of Hospitals. I would also like to thank Mr. S. Cohen, Mr. J. C. Morris, and Mr. N. Stephens for permission to study patients under their care.

\section{References}

Carey, J. S., Brown, R. S., Woodward, N. W., Yao, S. T., and Shoemaker, W. C. (1965). Surgery, Gynecology and Obstetrics with International Abstracts of Surgery, 121, 1059 .

Chien, S., Usami, S., Taylor, H. M., Lundberg, J. L., and Gregersen, M. J. (1966). Fournal of Applied Physiology, 21, 81 .

Dintenfass, L. (1969). American Heart fournal, 77, 139. intenfass, L., Julian, D. G., and Miller, G. E. (1966). American Heart Fournal, 71, 587.

Dormandy, J. A. (1970). Annals of the Royal College of Surgeons of England, $47,211$.

Gelin, L. E., Solvell, L., and Zederfeldt, B. (1961). Acta Chirurgica Scandinavica, 122, 309.

Gianelli, S., Ayres, S. M., Goldstone, R. A., Varriale, P., and Buehler, M. E. (1965). Fournal of Surgical Research, 5, 404.

Gregerson, M. I., Peric, B., Usami, S., and Chien, S. (1963). Proceedings of the Society for Experimental Biology and Medicine, 112, 883. 
Groth, C. G., and Thoren, G. (1965). Acta Chirurgica Scandinavica, 130,

Langsjoen, P. H., and Inmon, T. W. (1968). Angiology, 19, 247

Mayer, G. A. (1964). Canadian Medical Association fournal, 91, 951.

Poiseuille, J. L. M. (1846). Comptes Rendus Hebdomadaires des Séances de l'Académie des Sciences, 9, 433.
Skovborg, F., Nielsen, A. V., Schlichtkrull, J., Ditzel, J. (1966). Lancet 1,129

Skovborg, F., Nielsen, A. V., and Schlichtkrull, J. (1968). Scandinavian Fournal of Clinical and Laboratory Investigation, 21, 83.

Wells, R. E. (1966). Bibliotheca Anatomica, 9, 520.

Yao, S. T., and Shoemaker, W. C. (1966). Annals of Surgery, 164, 973.

\title{
Glucagon in the Treatment of Paget's Disease of Bone
}

\author{
JOHN R. CONDON
}

British Medical fournal, 1971, 4, 719-721

\section{Summary}

Glucagon given by intravenous infusion at a dosage of 0.2 to $0.8 \mathrm{mg} / \mathrm{hour}$ to four patients with Paget's disease of bone resulted in a dramatic fall in plasma alkaline phosphatase. This was associated with a fall in 24-hour urinary calcium and in total urinary hydroxyproline excretion and a marked relief of bone pain.

Glucagon may induce these changes by three possible mechanisms: (1) by stimulating release of calcitonin; (2) by a direct action of the hormone on bone; and (3) by stimulation of certain bone pyrophosphatases, thus altering the local mechanisms controlling the rate of bone formation and resorption.

\section{Introduction}

Calcitonin has been reported to induce clinical and biochemical remission in patients with Paget's disease of bone (Bijvoet et al., 1968; Woodhouse et al., 1971). Glucagon might also be expected to be of benefit in this disorder since it stimulates release of calcitonin from the thyroid gland (Care et al., 1970a).

Clinical and biochemical results in four patients with Paget's disease of bone treated with glucagon are reported. The mode of action of the hormone in this disorder is discussed.

\section{Methods}

Total urinary hydroxyproline was measured by the method of Grant (1964) modified by Pennock et al. (1970). Plasma alkaline phosphatase was measured by the method of Kind and King (1954), plasma calcitonin (Dr. G. V. Foster) by a radioimmunoassay technique (Clark et al., 1969), urine calcium by flame spectrophotometry (MacIntyre, 1960), plasma calcium by EDTA titration (Gehrke et al., 1954), and plasma phosphate by the method of Kraml (1966).

Glucagon Therapy.-Glucagon was dissolved in $500 \mathrm{ml}$ of normal saline and administered by slow intravenous infusion. The rate of giving glucagon varied from 0.2 to $0.8 \mathrm{mg} /$ hour. In Cases 1 and $21 \mathrm{mg}$ was given intravenously as an initial dose; this was designed to stimulate release of calcitonin, which was assayed in these two patients.

\section{Case 1}

A 65-year-old man with bone pain had radiological evidence of extensive osteitis deformans. Plasma calcium was $9.4 \mathrm{mg} / 100 \mathrm{ml}$,

St. George's Hospital, London S.W.1

JOHN R. CONDON, B.SC., M.R.C.P., Senior Registrar plasma phosphate $3.9 \mathrm{mg} / 100 \mathrm{ml}$, and plasma alkaline phosphatase 109 King-Armstrong (K.A.) units $/ 100 \mathrm{ml}$.

Treatment with glucagon resulted in a dramatic fall in plasma alkaline phosphatase which was most pronounced on the fifth and sixth days (Fig. 1). It began rising slowly on the ninth, tenth, and eleventh days, this rise possibly being due to a reduction in the dose of glucagon given on the third and fourth days. Increasing glucagon dosage on the fifth and eighth days of treatment resulted in a further steep fall in plasma alkaline phosphatase to 56 K.A units $/ 100 \mathrm{ml}$. The total fall in plasma alkaline phosphatase was 52 K.A. units $/ 100 \mathrm{ml}$ during nine days of glucagon therapy. The

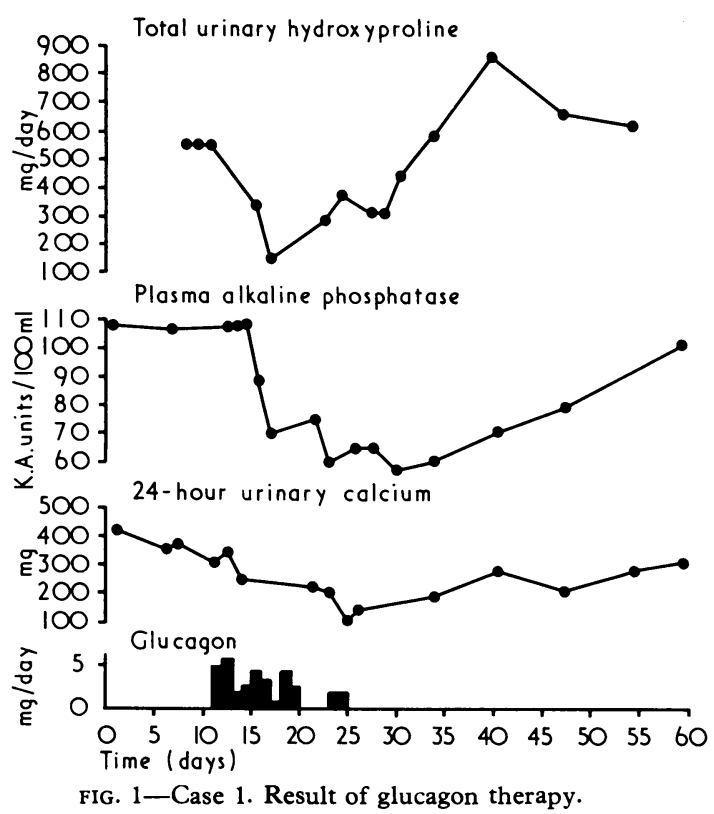

urinary calcium fell from a mean value of $379 \mathrm{mg} / 24$ hours before treatment to $78 \mathrm{mg} / 24$ hours. Total urinary hydroxyproline also fell during therapy. Plasma calcium values remained within normal limits during therapy but there was an intermittent fall in plasma phosphate to $3.3 \mathrm{mg} / 100 \mathrm{ml}$.

Relief of bone pain occurred six days after beginning treatment but when glucagon was stopped mild bone pain returned within 12 days and this became more severe 26 days after stopping glucagon. Recurrence of bone pain was accompanied by a rise in plasma alkaline phosphatase, total urinary hydroxyproline, and urinary calcium values, thus confirming that the clinical and biochemical changes noted were the result of glucagon therapy. Calcitonin was undetectable (less than $500 \mathrm{pg} / \mathrm{ml}$ ) in blood samples taken immediately before and at 15,30 , and 240 minutes after initial glucagon infusion.

\section{Case 2}

A 76-year-old woman with clinical and radiological evidence of Paget's disease of bone was also treated with glucagon. The plasma alkaline phosphatase fell from 160 to 64 K.A. units $/ 100 \mathrm{ml}$ within 